\title{
UNIVERSUM
}

$10.4067 /$ So718-23762021000200329

Revista de Humanidades y Ciencias Sociales
ISSN: o $078-2376$ (En linea)

\section{ESTO NO ES UN MUSEO: THE SKOGHALL KONSTHALL DE ALFREDO JAAR Y LIMAC DE SANDRA GAMARRA ${ }^{I}$}

\author{
This is not a museum: The Skoghall Konsthall of Alfredo Jaar y LiMAC of Sandra Gamarra
}

\author{
Megumi Andrade Kobayashi' (iD) \\ ${ }^{` E s c u e l a ~ d e ~ L i t e r a t u r a, ~ U n i v e r s i d a d ~ F i n i s ~ T e r r a e, ~ C h i l e . ~}$
}

\section{RESUMEN}

A comienzos de siglo, en las ciudades de Skoghall, Suecia, y Lima, Perú, los artistas Alfredo Jaar (Santiago, 1956) y Sandra Gamarra (Lima, 1972), fundaron dos particulares museos de arte contemporáneo: The Skoghall Konsthall y LiMAC. Debido a que -hasta ese entonces- ninguna de estas ciudades contaba con uno, Jaar y Gamarra pretendieron suplir ese vacío con sus respectivos proyectos. En este ensayo analizaré algunas de las interrogantes que ambos museos enuncian en relación con los mecanismos artísticos y las prácticas sociales vinculadas a este tipo de instituciones. Junto con esto, planteo que la estrategia central de la retórica de The Skoghall Konsthall y el LiMAC consiste en la negación.

PALABRAS CLAVE: Alfredo Jaar; Sandra Gamarra; The Skoghall Konsthall; LiMAC, Museo de arte contemporáneo.

\section{ABSTRACT}

At the beginning of this century, in the cities of Skoghall, Sweden, and Lima, Perú, the artists Alfredo Jaar (Santiago, 1956) and Sandra Gamarra (Lima, 1972), founded two special museums of contemporary art: The Skoghall Konsthall and LiMAC. Because -until then- none of these cities had one, Jaar and Gamarra intended to supply that void with their respective projects. In this essay, I will analyze some of the issues that both museums set up in relation to the artistic mechanisms and the social practices associated to this kind of institutions. Besides, I suggest that the central strategy of the rhetoric of The Skoghall Konsthall and LiMAC consists in the negation.

KEYWORDS: Alfredo Jaar; Sandra Gamarra; The Skoghall Konsthall; LiMAC; Contemporary art museum.

\section{Fecha de Recepción 2020-OI-I9}

Fecha de Aceptación $2020-04-17$

'Este artículo forma parte del Proyecto Fondecyt Regular iı6ro2I, "Poéticas negativas". 


\section{ANTI-MUSEOS}

En 1968, el poeta y artista belga Marcel Broodthaers (1924-1976) fundó, en su casa de Bruselas, su propio museo. Musée d'Art Moderne, Département des Aigles era su nombre, y si bien no contaba con un edificio que lo albergara -mucho menos una colección permanente- a partir de ese año y hasta 1972 Broodthaers realizó, en distintos lugares, una docena de instalaciones. Partiendo de temas tales como folklor, cine, literatura y arte moderno, estas instalaciones fueron compuestas a partir de reproducciones de obras de arte, dibujos, películas, fotografías, textos museográficos, embalajes, marcos vacíos, entre otros objetos. ${ }^{2}$ Cada instalación correspondía a una sección del museo, y el águila, símbolo comúnmente asociado al poder y la victoria, era su emblema. En ocasiones, los objetos exhibidos se encontraban meticulosamente etiquetados con un número, debajo del cual se inscribía la leyenda "esta no es una obra de arte", en directa referencia a la famosa pintura de Magritte. Inspirado por las revueltas estudiantiles de $1968,{ }^{3}$ e influenciado por el trabajo de artistas como Marcel Duchamp y el mismo Magritte, el Musée d’Art Moderne fue concebido como el fin de criticar y parodiar las instituciones artísticas oficiales, y repensar la relación entre arte y sociedad.

Así como en 1968 Marcel Broodthaers fundó este proyecto -expandiendo de ese modo su trabajo artístico hacia una labor de curador, e incluso administrador y agente de prensa- poco más de treinta años después, dos latinoamericanos, Alfredo Jaar (Santiago, 1956) y Sandra Gamarra (Lima, 1972), siguieron la senda del artista belga y crearon sus propios museos: The Skoghall Konsthall (2000) y LiMAC, Museo de Arte Contemporáneo de Lima (2002). El primero de ellos fue completamente quemado veinticuatro horas después de su inauguración, en la ciudad sueca de Skoghall, mientras que el segundo sigue operando, hasta el día de hoy, en distintos formatos.

Si bien los museos de Jaar y Gamarra guardan familiaridad con el de Broodthaers, los distingue el hecho que su creación estuvo impulsada por un vacío urbano e institucional; hasta ese entonces, ni Skoghall ni Lima contaban con un museo de arte contemporáneo. Además de este carácter edificador, The Skoghall Konsthall y LiMAC se emparentan con una práctica artística que estudia Mathieu Copeland, curador de la exposición "A Retrospective of Closed Exhibitions". ${ }^{4}$ A partir de la década de los sesenta, señala en autor, numerosos artistas -varios de ellos vinculados directa o indirectamente al arte conceptual-comienzan a clausurar la entrada de galerías y museos.

\footnotetext{
${ }^{2}$ Según señala Dirk Snauwaert en el número 5 de The artist as a curator, los doce temas de estas secciones fueron: "literary, documentary, I7th century, folkloric, cinema, financial, figure, publicity, modern art, I9th century, I9th century bis, and 2oth century".

${ }^{3}$ Meses antes de su fundación, junto a otros artistas y estudiantes, Broodthaers participó en la toma del Palais des Beaux Arts de Bruselas.

${ }^{4}$ Realizada en el centro de arte Fri Art en Fribourg, Alemania (del 5 de agosto al ig de noviembre de 2016).
} 
Por motivos que van desde la necesidad, a la burla, a la crítica, etc., y a partir de distintas estrategias y materiales, Robert Barry, Matsuzawa Yukata, Santiago Sierra y Graciela Carnevale, entre muchos otros, se han planteado cuestionar -por esta vía- los límites del arte. En la antología The Anti-Museum, Copeland propone: "In these uncompromising pieces, we are confronted with a closed space, and invited to experience its physical, sensory and conceptual realities" (38). A pesar de que los museos de Jaar y Gamarra parecen hacer exactamente lo contrario (fundar un museo en lugar de cerrarlo), veremos de qué forma en ambos ocurre también una clausura. Y es que, junto con proponer una posible -y, en el caso de Jaar, efímera- solución, tanto en The Skoghall Konsthall como en el LiMAC se niega el acceso al museo: en el primero al quemarlo, y en el segundo al suplantarlo con una tienda de souvenirs. Estas negaciones serán, precisamente, el hilo conductor de este ensayo.

\section{THE SKOGHALL KONSTHALL}

En un breve texto del 2008, Adriana Valdés bosqueja una suerte de poética de la obra de Alfredo Jaar. La existencia de un problema real, el desarrollo de un cuidado proceso de investigación y una especial atención al contexto en el que cada obra se origina, son tres ejes fundamentales de la manera en la que, según la autora, Jaar ha llevado a cabo gran parte de su obra. "Los hechos reales se plantean como problemas y la obra es el resultado de una programación de actividades, que incluyen la investigación acerca del lugar y todas las etapas de producción y montaje" (I2). El "hecho real" que motivó la creación de esta obra se relaciona con la historia de Skoghall, una pequeña ciudad sueca que fue construida casi por completo por la papelera más grande del mundo, la multinacional Stora Enso, con el fin que los trabajadores pudieran vivir cerca de sus fábricas. Además de levantar gran parte de la infraestructura de la ciudad, la empresa financió colegios, hospitales e iglesias; instituciones y espacios que se consideraron necesarios para que los habitantes de Skoghall sintieran que vivían en una ciudad como cualquier otra.

El inicio de la relación entre Jaar y Skoghall comienza cuando, en el 20oo, el municipio se contactó con él para comisionarle la realización de una obra de arte pública (Doherty, II). Sin embargo, cuando se enteró que la ciudad no contaba con un espacio dedicado al arte o la cultura, declinó la oferta. Como afirma en una entrevista: "I was shocked to discover that a community

\footnotetext{
5 "En estas intransigentes piezas, nos confrontamos a un espacio vacío y somos invitados a experimentar sus realidades físicas, sensoriales y conceptuales" (trad. de la autora).
} 
could exist for thirty years without any visible cultural or exhibition space" (Philips). La solución que Jaar ideó para enfrentar esta falta fue conseguir que Stora Enso le financiara la creación de un museo de papel. Lo que tenía en mente era generar una instancia de encuentro en torno al arte y, con esto, promover una toma de consciencia en los habitantes respecto de cuán importante era, para ellos mismos, que su ciudad contara con un espacio de exhibición e intercambio artístico.

Para realizar The Skoghall Konsthall, se convocó a quince artistas suecos a que expusieran al interior del museo. Salvo por las vigas y los soportes de madera, el edificio fue construido completamente a partir de papel. Todas las obras debían ser realizadas con este material ya que, tal como fue explicitado en la propuesta del artista, veinticuatro horas después de inaugurada la muestra, el edificio sería incendiado. ${ }^{7}$ En este sentido, se trató de lo que -desde el ámbito de la arquitectura- se conoce como arquitectura efímera, eventual o impermanente: una construcción realizada para un contexto puntual (una emergencia, una conmemoración, un evento específico) y que, indefectiblemente, ha de ser desmantelada luego de un período determinado (Vidler, 207).

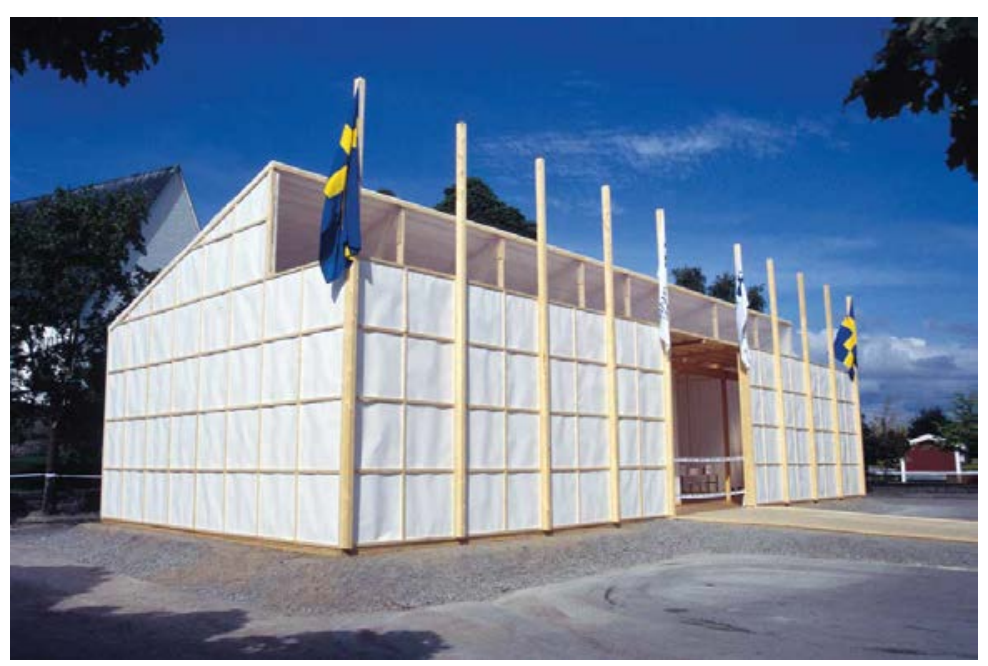

FIGURA r: Fotografia de The Skoghall Konsthall (Fuente: Página web de Alfredo Jaar. https://cutt.ly/4RoEHou)

La segunda regla que Jaar impuso a los artistas invitados fue que las obras provocaran una participación activa del público. Como relata Francisco Godoy en su ensayo "Ante los museos", uno de los trabajos expuestos invitaba a los visitantes a realizar figuras de origami, otro la tarea de transcribir conversaciones telefónicas cuyo contenido se relacionaba con el mismo museo. De este modo, a partir de su materialidad y los criterios curatoriales, se procuró que The Skoghall Konsthall dialogara directamente con la historia de la ciudad y con sus habitantes.

\footnotetext{
6 "Me impactó descubrir que una comunidad pudiera existir por treinta años sin un espacio cultural o de exposiciones" (Trad. de la autora).

7 De esto estaban al tanto las autoridades y los habitantes de la ciudad.
} 
El día de la apertura del museo de papel se reunió una gran cantidad de gente en la entrada. Tuvo lugar una ceremonia de carácter oficial: estaban presentes las principales autoridades y el alcalde procedió a cortar una cinta que delimitaba la entrada, acto con el cual se dio inicio a la exhibición. En YouTube se puede revisar un video que registró todo el proceso: en términos de público y participación, la muestra parece haber sido un éxito. ${ }^{8}$ Pasadas las primeras horas surgió, no obstante, una polémica, un conflicto que Jaar -según confesó más tarde- esperaba que sucediera. Los habitantes de Skoghall se opusieron a que se llevara a cabo la segunda parte del proyecto; es decir, se negaron a que el museo fuera quemado. Como relata Michael Corris, "The townspeople protested: this is a beautiful and necessary structure that must not be destroyed"9 (7). A pesar de las resistencias, ya que para Jaar la última etapa de la intervención era decidora, el plan siguió su curso. ${ }^{10}$ Luego de veinticuatro horas, frente a una muchedumbre que lo contemplaba desde la distancia, el museo fue completamente incendiado.

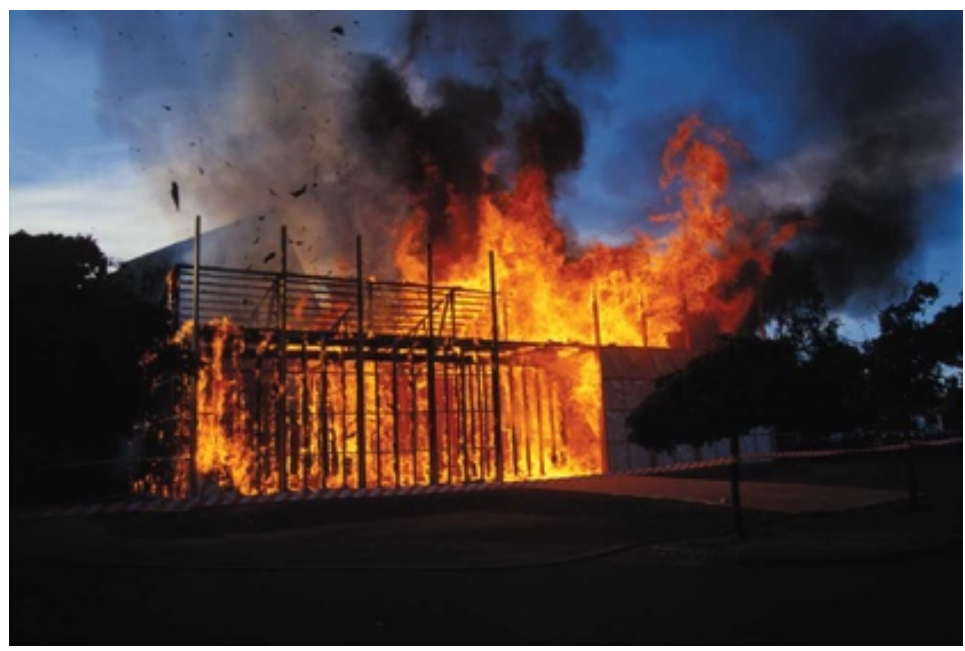

FIGURA 2: Fotografía de The Skoghall Konsthall en pleno incendio. (Fuente: Página web de Alfredo Jaar. https://cutt.ly/4RoEHou

"Ojos que no ven, corazón que no siente", reza el dicho popular. Su moraleja es simple: lo que no se ve, no afecta. De la misma manera, se podría pensar que una ausencia que no se percibe no es -en realidad- una ausencia. Como hemos visto, remediar una ceguera fue precisamente el principal objetivo de la intervención de Jaar. No obstante, este propósito se llevó a cabo de modo inverso a lo que se podría esperar; y es que, más que hacer visible la ausencia por medio de la construcción del museo, fue fundamental -en términos retóricos- negarlo, destruirlo.

\footnotetext{
${ }^{8}$ Véase el video en el siguiente enlace: https://cutt.ly/gRoE4LP

9 "La gente de pueblo protestó: este es una hermosa y necesaria estructura que no debe ser destruida" (trad. de la autora).

${ }^{\text {ro }}$ Incluso declinó una propuesta de desmantelar el edificio y reciclar los materiales para construir un sector de juegos para los niños de la ciudad (Corris, 7).
} 
Como advierte Nicole Schweizer, una recurrente estrategia de representación en los proyectos de Jaar consiste en contraponer algo ausente con algo presente. ${ }^{\text {II }}$ Por su parte, Adriana Valdés afirma que sus obras hacen "visible algo que no entra en los esquemas de pensamiento del espectador, algo que los descentre y los perturbe, algo que aparezca como ajeno... pero que al mismo tiempo en cierto sentido seduzca, logre introducir una cuña de inquietud en los sistemas de certidumbres" (387). Como vimos, en el museo de papel esta visibilización se realizó a partir de una detallada orquestación que consistió en planificar, construir, curar, montar, inaugurar y destruir. Mirado en su conjunto, claramente se trató de un proceso de carácter pedagógico. No obstante, por la manera en que se llevó a cabo, se trata de una enseñanza basada en el castigo, con lo cual aparece el carácter aleccionador e incluso paternalista de la obra.

El efecto de visibilización que buscaba el artista se logró, especialmente, gracias al carácter espectacular y dramático del incendio. Como en un ritual (el fuego jugó un rol protagónico), un mensaje fue revelado, algo que -según Jaar- los habitantes de Skoghall no sabían, pero necesitan saber. Como escribe Adriana Valdés: "las llamas han de iluminar la falta total de una instancia de reunión y de pensamiento, de comunicación artística y creativa, en la localidad de Skoghall; queda en manos de sus habitantes la tarea de crearla" ${ }^{92}$ (387). En la planificación del proyecto, el mismo Jaar revela la finalidad pedagógica de su obra, ${ }^{\mathrm{r} 3} \mathrm{y}$ en una entrevista que cita Claire Doherty en su libro Public Art (Now), afirma: "I wanted to offer a glimpse of what contemporary art is and what it can do in a community. Then by «disappearing» it in such a spectacular way, I hoped to reveal its absence" (II). ${ }^{14}$ Con el tono profético de esta última frase, cual místico que decide transmitir al mundo su visión, Alfredo Jaar asume un rol artístico que, en el marco del circuito del arte contemporáneo, brilla por su extemporaneidad. Y es que, con un proyecto como The Skoghall Konsthall, se revive la imagen del artista como actor social, como movilizador de ideas y proyectos comunitarios; incluso proyectos con eventuales incidencias históricas (al menos con ese espíritu lo formula Jaar en su declaración).

\footnotetext{
${ }^{\text {Ir }} \mathrm{La}$ autora está pensando, fundamentalmente, en las obras dedicadas a Ruanda, pero me parece que se puede extender el diagnóstico en un sentido más amplio.

${ }^{12}$ El resaltado es de la autora.

${ }^{13}$ En "Notas del Skoghall Konsthall, 1999", publicadas en la revista de arquitectura Ciento Diez, Jaar escribió: "Espero que esta combinación de creatividad y existencia efímera contribuya en definir la importancia del arte contemporáneo en nuestras vidas. Es parte de mis esperanzas que la extremadamente corta vida del Skoghall Konsthall haga visible el vacío en que viviríamos si no hubiera arte. Esta obra quizás lidere a la ciudad de Skoghall en la creación de los espacios necesarios y permanentes para la creación contemporánea" (en línea).

I4 "Quise ofrecer una mirada de lo que es el arte contemporáneo y de lo que puede hacer en una comunidad. Por medio de «desaparecerlo» de un modo tan espectacular, mi anhelo era revelar su ausencia" (trad. de la autora). El resaltado es de la autora.
} 
Para reforzar el efecto esperado, además de ser público el destino que sufriría el museo de papel, fue importante que los habitantes hubieran interactuado con las obras previamente; establecido el vínculo, este fue roto. Para qué hablar de la carga cultural asociada al acto de quemar una obra de arte y un museo. Y es que, por muy precario y efímero que haya sido, simbólica e institucionalmente The Skoghall Konsthall ya había sido bautizado y reconocido como museo. Esto me recuerda a algo que subraya Mathieu Copeland en relación con las obras que antologa en su libro Anti-Museum, las cuales, en sus propias palabras: "remind ourselves of the necessity of any institution to show the most radical art, even if to show implies to close"15 (Copeland, 39). Y es que, al igual que las exposiciones cerradas de Robert Barry, Matsuzawa Yukata, Santiago Sierra y Graciela Carnevale, la efectividad de la obra de Jaar se sostiene, sobre todo, en que su museo de papel haya sido reconocido como tal antes de ser destruido. Ese reconocimiento se produjo, en gran medida, gracias al proceso curatorial, al montaje y toda la parafernalia oficial que se llevó a cabo el día de su inauguración. En este sentido, la clausura que realiza Jaar establece una contraposición similar a los anti-museos que estudia Copeland: se trata de una negativa que permite visibilizar aspectos tanto estéticos como políticos que normalmente permanecen en segundo o tercer plano. Así como un museo o una galería cerrada nos conduce a percibir y pensar, por ejemplo, sus aspectos conceptuales, sensoriales y físicos, el museo de Jaar nos lleva también a hacernos este tipo de interrogantes. En especial conduce a preguntarnos por el rol y el estatuto de este tipo de espacios en relación con una población determinada.

En uno de sus estudios más conocidos, el antropólogo Marc Augé plantea el concepto de "no-lugar" para referirse a aquellos espacios de paso, sin identidad ni historia, en los que no es posible habitar, sino solo transitar anónimamente. Carreteras, habitaciones de hotel, aeropuertos, supermercados y condominios habitacionales son algunos de los no-lugares más emblemáticos. Como contraposición a ellos, para el autor un ejemplo de "lugar" sería, por ejemplo, un monumento: según Augé, un espacio en el cual es posible compartir y conmemorar (III). Si miramos la intervención pública de Jaar desde este punto de vista, se podría pensar que la operación que llevó a cabo consistió en situar en el centro de un "no-lugar", "un lugar". Y es que, antes del museo de papel, Skoghall no era más que un conjunto de casas, "un complejo («grupo de casas habitación nuevas»), donde no se vive juntos y no se sitúa nunca en el centro de nada (grandes complejos: símbolo de zonas llamadas periféricas)" (Augé, Iıо-III). Gracias al efecto que generó un simple y austero museo de papel -la intervención fue todo un éxito y actualmente Skoghall tiene su

i5 "Nos recuerdan la necesidad de una institución para mostrar el arte más radical, incluso si la exhibición implica una clausura" (trad. de la autora). 
propio museo- la ciudad cambió, se transformó. En relación con esto, es interesante lo que Antony Vidler escribe en relación con la arquitectura efímera:

A pesar de que la arquitectura eventual o impermanente no deja rastros o huella después de cumplir su plazo útil, ésta se esmera por modificar radicalmente el espacio en el cual se inserta. Sus tácticas de inserción no obedecen las leyes del lugar, sino que se apropian de él, lo manipulan y utilizan transversal e ingeniosamente (207).

Como hemos visto, el proyecto de Jaar no solo alteró espacialmente la ciudad, sino que además se propuso modificar la relación entre esta y sus habitantes. De hecho, durante las veinticuatro horas en que los habitantes pudieron visitar el museo de papel, se formó un comité que estaría encargado de gestionar la construcción de un museo permanente para la ciudad. Siete años después, a Alfredo Jaar le llegó una carta en la que le solicitaron llevar a cabo ese proyecto (Thorp, "Alfredo Jaar: A Model of Thinking").

\section{LiMAC}

"Virtual", "en movimiento" o "itinerante" es como se suele describir el museo fundado por Sandra Gamarra en el año 2002. Y es que, a diferencia de un museo tradicional, este no tiene ni ha tenido un espacio físico ni mucho menos definitivo. El LiMAC existe por medio de una serie de productos de merchandising, exposiciones realizadas en distintos espacios y una página web en la cual se aloja un archivo que está en permanente actualización. A pesar de esta particularidad, según Gamarra el LiMAC no debiera ser comprendido como un proyecto ideal o personal, mucho menos imaginario, sino como un museo real, "the reflection of what would be a museum of contemporary art in Lima, with all its pretensions and defects"16 (Gamarra, "Emergencies Catalogue, Castilla y Leon Museum of Contemporary Art, 2005"). Al igual que The Skoghall Konsthall, el LiMAC fue creado debido a que no existía un espacio como ese en la capital peruana. Eso sí, en lugar del sentido pedagógico y aleccionador de la intervención pública de Jaar, Sandra Gamarra aclara que su iniciativa respondió a los deseos de una comunidad artística que llevaba décadas reclamando por un espacio donde fuera posible exponer, discutir y crear arte.

Originalmente, el LiMAC surgió como un proyecto web: el proyecto consistió en crear una página (www.li-mac.org), cuyo formato fuese lo más similar posible al sitio oficial de un museo

\footnotetext{
16 "El reflejo de lo que sería un museo de arte contemporáneo en Lima, con todas sus pretensiones y defectos" (trad. de la autora).
} 
común y corriente. Esta similitud es así por cosas tan simples como un logo o una serie de links que indican: "Acerca de LiMAC", "Amigos del museo", "Contáctanos", "Normas de ingreso" "Dirección", "Copyrights", etc. ${ }^{17}$

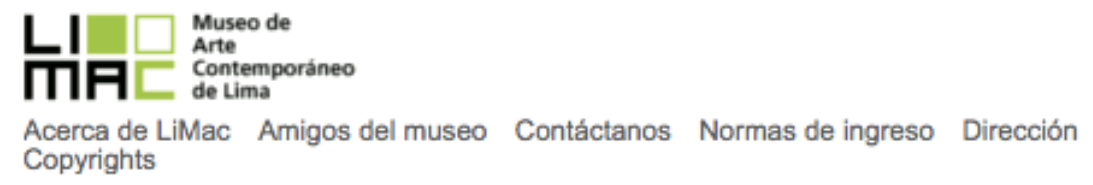

FIGURA 3: Captura de pantalla del sitio web del LiMAC. (Fuente: sitio web del LiMAC. http://i-mac.org/)

Al pinchar el vínculo "Dirección" aparece una nota importante, en especial para un lector no enterado del proyecto. Esta señala: "dado su naturaleza de verdadero falso museo, el LiMAC no tiene dirección permanente y aparece de vez en cuando en lugares distintos". Efectivamente, estas apariciones esporádicas -y algo parasitarias- comenzaron a realizarse en diferentes lugares de Lima, teniendo bastante éxito entre el público local. Hoy en día, el LiMAC ha realizado exhibiciones en ciudades como São Paulo (para la 29 Bienal de la misma ciudad), y Madrid.

Progresivamente, el LiMAC fue creciendo como proyecto. En el 2006, la oficina mexicana de arquitectos PRODUCTORA diseñó los planos de un edificio virtual, cuyo concepto fue ideado por la misma artista. ${ }^{18}$ También se realizaron numerosas exposiciones con artistas y curadores invitados. ${ }^{19}$ En todas estas instancias se exhibieron las obras que habrían de conformar la colección del LiMAC, obras que a partir de fotografías digitales comenzaron a habitar la página web. Esta, al igual que cualquier sitio de un museo, contiene vínculos que permiten acceder a contenidos tales como: "Noticias", "Exposiciones", "Colección", "Archivos", "Proyecto Arquitectónico", "Tienda", "Publicaciones" y "Biblioteca".

\footnotetext{
${ }^{17} \mathrm{Al}$ pinchar en cada una de estas categorías, nos encontramos con indicaciones un poco irónicas. En "Normas de ingreso", por ejemplo, se señala: "Li-MAC.org está abierto a todo público (animales incluidos)"; declaración impensable en un museo real, en cuyas puertas, boleterías y folletos suele aparecer el ícono de un perro atravesado por una cruz. Si nos vamos al link "Amigos del museo", leemos: "los amigos del LiMAC no necesitan hacer largas filas para ingresar al museo, ya que con el registro realizado desde este website pueden acceder a una entrada electrónica". Aquí el engaño es un poco más complejo que el anterior; podríamos pensar que la invitación es a hacemos miembros de la red de amigos o colaboradores del Museo -como de hecho ocurre normalmente es espacios como el Whitney Museum, el Reina Sofía, el MALBA, etc.- con lo cual tendríamos el beneficio de saltarnos una fila imaginaria de un museo inexistente.

${ }^{18}$ Como aparece en el catálogo del proyecto arquitectónico, que se puede descargar de la misma página web: "El museo conservaría los «clásicos» espacios ortogonales y, como edificio, debería desaparecer en el paisaje desértico de las afueras de Lima". Por supuesto, el edificio nunca se construyó.

19 Algunas de las primeras exhibiciones fueron Souvenir (Lima, 2002), Curso por correspondencia (Lima, 2003), Visita guiada (Madrid, 2003) y Nuevas adquisiciones (Lima, 2006).
} 


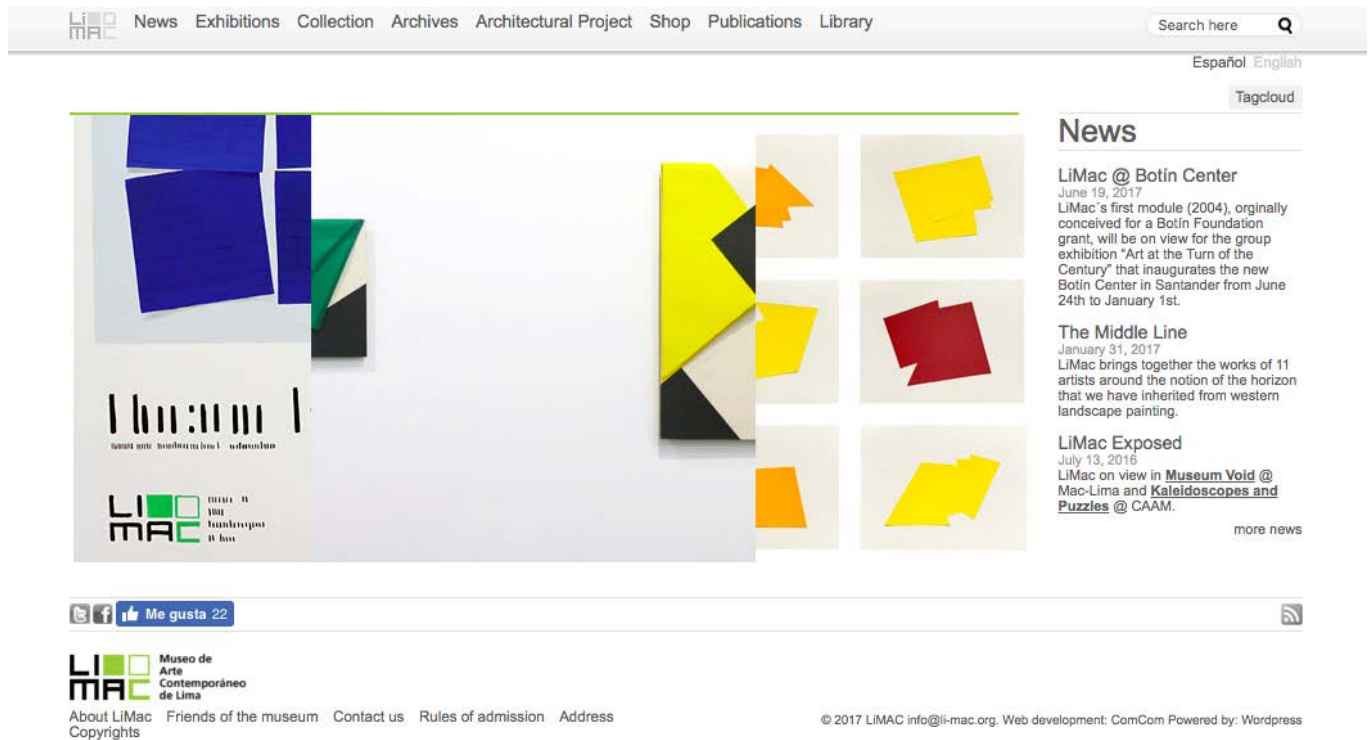

FIGURA 4: Captura de pantalla del sitio web del LiMAC. (Fuente: sitio web del LiMAC. http://li-mac.org/)

La importancia de la tecnología digital y de internet para la realización de este proyecto es evidente. Como es sabido, hoy en día las herramientas que permiten crear páginas web y llenarlas de contenido -visual, audiovisual y sonoro- son inmensas y de fácil acceso. Incluso, existen distintas plataformas en las cuales no es siquiera necesario pagar para alojar un sitio. Esto es relevante porque si bien $L i M A C$ se ha llevado a cabo a partir de exhibiciones esporádicas en distintos lugares, sigue siendo fundamental su condición de página web, a la cual permanentemente se la está actualizando de contenidos y noticias. De hecho, con el tiempo se ha convertido en un archivo de obras de arte contemporáneo de fácil acceso, lo cual lo emparenta con lo que actualmente se conoce como "museos virtuales", los cuales, a su vez, hacen eco del famoso "museo imaginario" de Malraux. ${ }^{20}$

Ahora bien, lo interesante es qué tipo de obras son las que fundan inicialmente el LiMAC (y, de paso, la Colección del museo): fotografías digitales de pinturas que realiza Sandra Gamarra a partir de imágenes de obras que han sido publicadas en catálogos y libros de arte contemporáneo.

Con respecto a esto, la artista propone: "Through the materiality of painting this collection of copies becomes true. Painting ends up becoming a weapon of reality that carries the falseness of the collection of an inexistent museum. The catalogue turned into painting, painting ${ }^{20}$ A un museo virtual se puede acceder por internet, es interactivo con el usuario y, en ocasiones, sus contenidos son de
libre acceso. 
turned into a catalogue"2⿰ (Gamarra "Emergencies"). Estamos ante un museo de copias, un museo que -ante la precariedad económica y cultural de la capital peruana- decide crear su colección a partir de falsificaciones. Para esto, en un principio no fue necesario contar con grandes financiamientos ni millonarias becas;22 la ética del D.I.Y. ("Do it Yoursefl") y una práctica tan común en el contexto latinoamericano como la realización de copias falsificadas, resolvieron el problema. ${ }^{23}$ Esto es tan así -tan derechamente programático- que la descripción de una de las colecciones más importantes del museo señala:

La Colección Bamba está formada por obras de arte copiadas en pintura al óleo por Sandra Gamarra-Heshiki a partir de publicaciones de arte contemporáneo. La colección se enfoca en copias de instalaciones, esculturas, fotografías y videos. Las obras tienen como título el número de la página de la publicación fuente. Cada copia permite al LiMAC la oportunidad de exponer estas obras "originales" a un público más amplio. Debido a la escasa importación de productos extranjeros a lo largo de los años 60 y 7o, el Perú ha desarrollado una gran economía de marcas falsas y alteradas de ropas, libros y otros productos conocidos como productos Bamba. Hoy en día esta cultura de copia todavía está muy presente. (LiMAC)

Desde el título, podemos pensar en esta colección del LiMAC como algo derivado, falso, pero también -en la medida en que lo "bamba" está en el límite de lo legal-como una operación que logra hacer patente la enorme presencia de las lógicas del mercado en el mundo del arte. De paso, se podría interpretar, también, una suerte de crítica irónica a la tendencia monopólica del circuito del arte contemporáneo por parte de ejes económicos y culturales como Londres, Nueva York, Chicago, etc. De hecho, en el número 9 de la revista Código, dedicada a distintos artistas latinoamericanos, Ruth Estévez menciona que "el LiMAC es también una ironía al sistema, la creación de un espacio gigantesco con obras que jamás formarán parte de una colección

\footnotetext{
21 "Valiéndose de la materialidad de la pintura esta colección de copias se hace verdadera. La pintura termina siendo un arma de la realidad que soporta la falsedad de la colección de un museo inexistente. El catálogo se convierte en pintura, la pintura se convierte en catálogo" (trad. de la autora).

${ }_{22}$ Posteriormente, la artista ha recibido becas para continuar desarrollando este proyecto. En el año 2004, por ejemplo, se adjudicó la Beca de Artes Plásticas de la Fundación Botín, con la cual realizó una exposición del LiMAC en ARCO (Feria de Arte Contemporáneo) de la ciudad de Madrid.

${ }^{23}$ Como es sabido, en la Europa del siglo XVIII se fundaron una serie de museos de copias, instituciones que tenían por finalidad difundir a un público más amplio las colecciones albergadas en los museos nacionales de arte. Según Ximena Gallardo Saint-Jean en la introducción de un libro recientemente publicado sobre este tema, la legitimación de estos museos estaba sostenida en la tradición académica, en la que el principio formativo estaba sostenido precisamente en practicar copias. Según la autora, en ese momento en particular "la copia era apreciada como una obra artística en sí misma, sin que por ello entrara a competir con el original" (IO). Si bien esta concepción fue cambiando a partir de comienzos del siglo XX, a lo largo de toda la segunda mitad del siglo XIX dicho modelo se importó con bastante fuerza a distintas naciones americanas, precisamente con el propósito de incentivar la formación artística de sus habitantes. Menciono esto porque me parece notable la coincidencia de la "Colección Bamba" del LiMAC con los primeros museos americanos que, debido a la distancia y la falta de presupuesto, armaron sus primeras colecciones a partir de versiones de modelos europeos. Lo que llama la atención es que en pleno siglo XXI en una capital como Lima se tenga que recurrir a una estrategia similar para suplir una carencia institucional como la que hemos revisado. En este sentido, el proyecto llevado a cabo por Sandra Gamarra dialoga, en parte, con esta tradición, pero al mismo tiempo reflexiona en torno a los modos en los que, desde América Latina, accedemos al arte contemporáneo.
} 
latinoamericana, por encontrarse ya en museos más centralizados" ("Perú"). A lo que habría que agregar: por encontrarse en museos centralizados y por el enorme costo que significaría levantar desde cero una colección de arte contemporáneo. De este modo, el LiMAC constituye su propia colección con el remedo de imágenes de obras de arte y exposiciones de otros artistas, imágenes distribuidas masivamente en catálogos y libros. Todo esto, a partir de óleo sobre lienzo -materiales tradicionales del ámbito de la pintura- y en formatos que, en el caso de la "Colección Bamba", llegan a los 195 x $195 \mathrm{~cm}$. En este sentido, podríamos leer esta transformación de escalas -de la fotito del catálogo al lienzo- en relación, nuevamente, al museo imaginario de Malraux, solo que aquí el proceso es inverso: de la imagen fotográfica a la pintura.

Si volvemos a los inicios del $L i M A C$, junto con la realización de la página web, en el mismo año 2002 el proyecto se materializó en una tienda móvil que fue instalada en el Museo de Arte de Lima (MALI). El puesto exhibía productos -tipo souvenirs- que normalmente encontramos en las tiendas de regalos de grandes museos, como tazas, lápices, posters, gorros, poleras, todos con el logo del LiMAC.

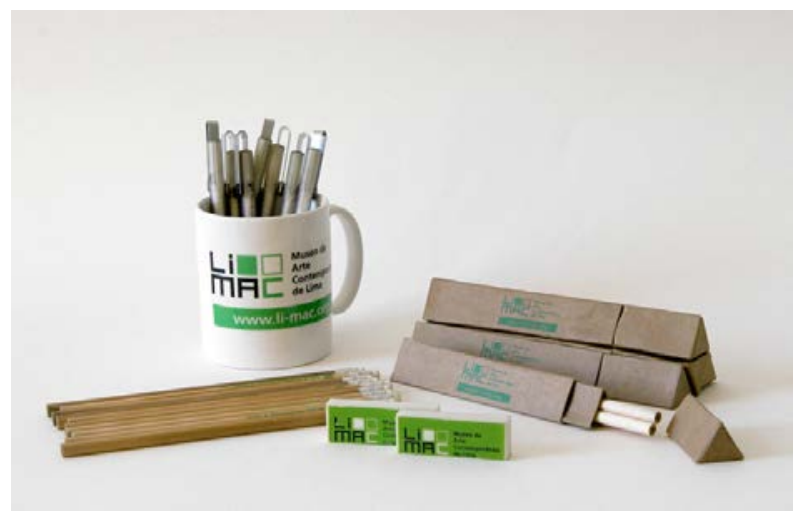

FIGURA 5: Souvenirs. (Fuente: sitio web del LiMAC. http://li-mac.org/)

En el mismo stand se encontraba un computador en el cual era posible navegar por la página web y recorrer, así, su contenido. Desde entonces, la tienda ha sido instalada en diversos espacios y ha cambiado la manera de ser expuesta: por ejemplo, una versión del 2004, "LiMAC Manta museo I", consistió literalmente en una manta blanca dispuesta sobre el piso. Sobre ella, como en una especie de picnic, se dispusieron todos los productos. En el 2012 la instalación llevó por nombre "Bodegón museo": era básicamente una mesa con todos los materiales encima, a la manera de una naturaleza muerta. 


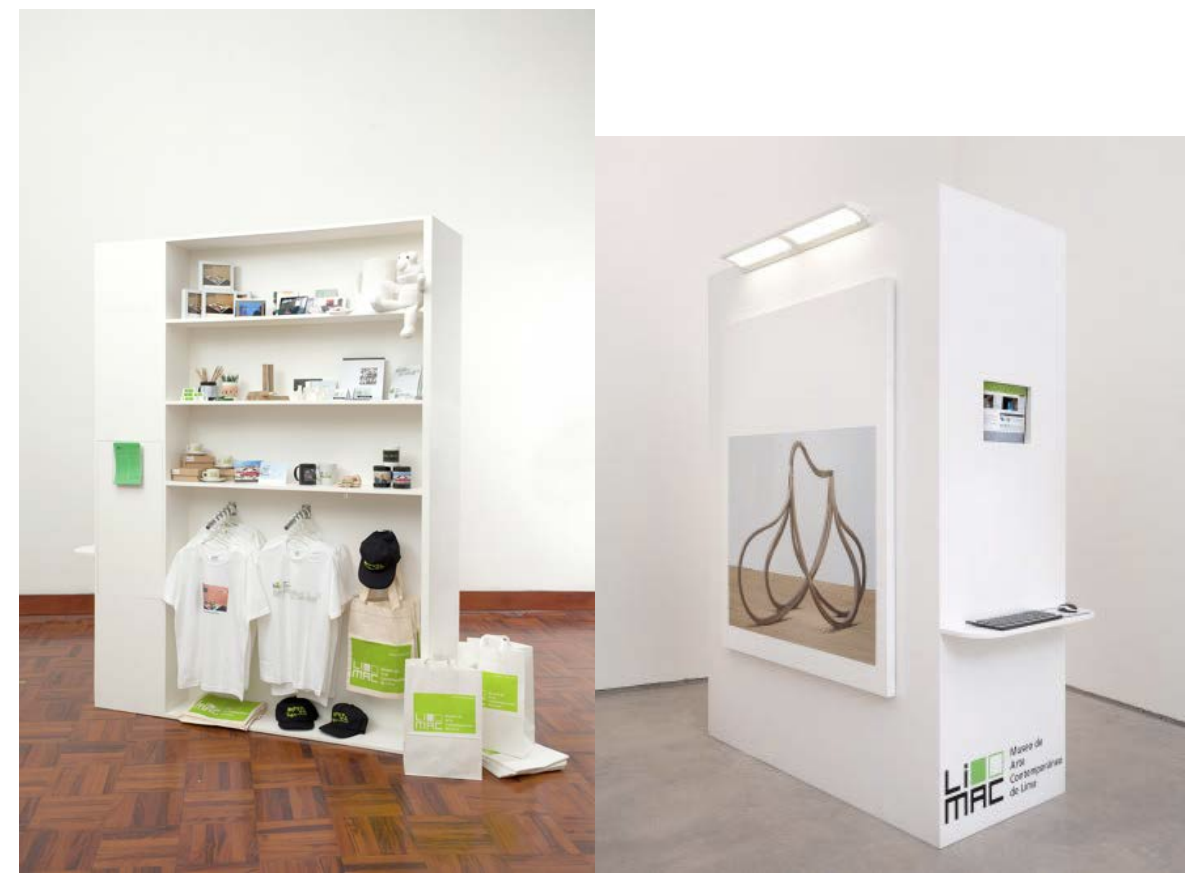

FIGURA 6: Sandra Gamarra. Módulo tienda LiMAC II, 2009. Técnica mixta, I97x240x80 cm. (Fuente: sitio web del LiMAC. http://i-mac.org/)

Junto con ser el recuerdo que algo que no ocurrió, estos productos refieren a una colección y a un museo que, en términos tradicionales, no existe. En este sentido, como indica la misma artista: "our museum has begun its construction from the end; it begins as a memory of what has not yet been lived"24 (Gamarra "Emergencies"). Junto con ser irónica, la inversión a la que hace referencia Sandra Gamarra supone que, si bien al suplantarlo la tienda le da existencia, al mismo tiempo hace patente que este no existe y que nunca será posible acceder a él. Como el fuego de Jaar, las tiendas de merchandizing simultáneamente afirman y niegan el museo.

Entre el recuerdo no vivido - de la visita- y los productos a la venta, aparecen una serie de interrogantes que, como iremos viendo, en lugar de apuntar al enaltecimiento de este tipo de espacios, articulan más bien a una mirada crítica. Tal vez lo más evidente de las tiendas del LiMAC es que ponen en relieve algo bastante común hoy en día: el hecho que la postal, la bolsa, el llavero o el lápiz, suelen funcionar como una suerte de prueba, un certificado de visita. ${ }^{25}$ Además, muchas veces un souvenir de museo opera como una suerte de reliquia, un fragmento que remite materialmente a un lugar culturalmente sagrado.

\footnotetext{
${ }^{24}$ "Nuestro museo ha empezado a construirse por el final, empieza por ser un recuerdo de lo que aún no se ha vivido" (trad. de la autora).

${ }^{25}$ En relación con esto, existe documental del artista callejero Banksy, Exit Through the Gift Shop (20ro), cuyo título que alude, irónica y críticamente, a una indicación que efectivamente existe en algunos museos.
} 
"Mantareina" es el nombre de una tienda del LiMAC que fue expuesta en el 2004 a la salida del Museo de Arte Reina Sofía, en Madrid. La instalación consistió, simplemente, en disponer en la vereda una manta blanca con algunos de los productos de merchandising del LiMAC.

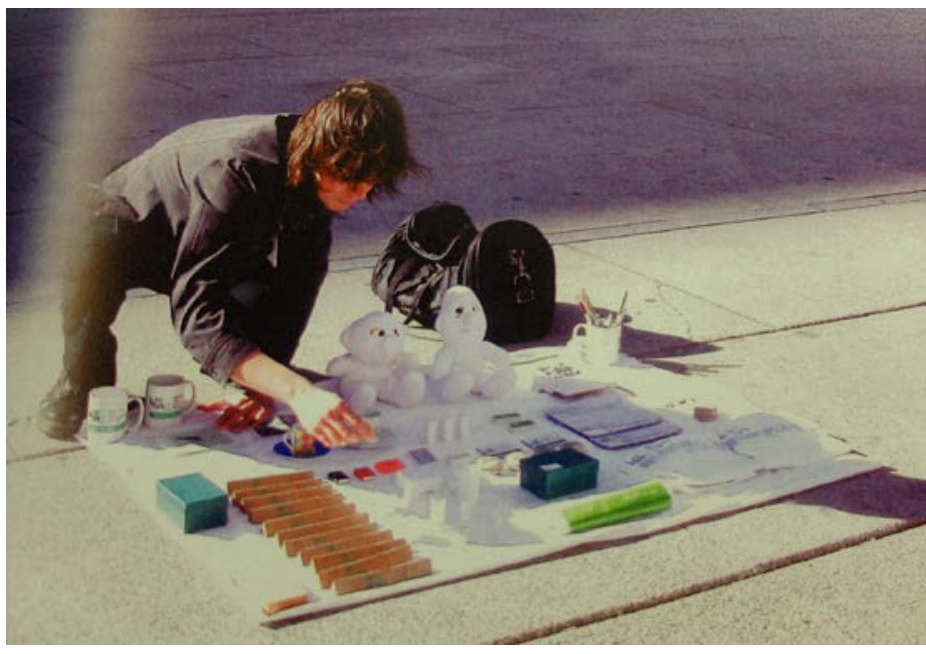

FIGURA 7: Fotografía de la instalación "Mantarreina" (Fuente: sitio web del LiMAC. http://i-mac.org/)

"The museum presents a museum as an exhibition object, the museum bites its tail", ${ }^{26}$ escribió Sandra Gamarra ("Emergencies Catalogue, Castilla y Leon Museum of Contemporary Art, 2005"). Si bien la mayoría de las tiendas del LiMAC han sido emplazadas al interior de otros espacios artísticos, en el caso de "Mantareina" ocurrió un desplazamiento hacia el espacio público. Así, la tienda de un museo inexistente - pero que ha sido fundado a propósito de una ausencia artística y cultural real- abandona el espacio resguardado del Museo Reina Sofía y se instala en la ciudad. Al igual que The Skoghall Konsthall, se trata de una intervención pública.

"Mantarreina" hace pensar en la figura de un vendedor ambulante que ofrece a los transeúntes versiones baratas de grandes marcas, lo cual se relaciona con la "Colección Bamba" y, en general, con el espíritu apropiacioncita del museo. Frente al Reina Sofía, esta tienda parece una broma: está todo dispuesto en el suelo y solo se ofrecen un par de peluches recubiertos de un tejido blanco, lápices, tazas y algunas poleras. Además, el hecho que se haya realizado en el exterior de un museo de esa envergadura se hace patente - por contraste- la precariedad cultural y artística del LiMAC y, de paso, de la capital peruana. En este sentido, a partir de su aspecto y disposición, se visibiliza la ausencia a partir de la cual fue fundado.

\footnotetext{
26 "El museo presenta un museo como objeto de exposición, el museo se muerde la cola" (trad. de la autora).
} 


\section{REFLEXIONES FINALES}

En una entrevista de 1972, Marcel Broodthaers afirmó: "It is also important to find out whether or not the fictional museum cast a new light on the mechanism of art, the artistic life, and society. I pose the question with my museum. Therefore, I do not find it necessary to produce the answer"27 (Copeland, 45). Emparentadas con Broodthaers, las obras de Jaar y Gamarra plantean interrogantes respecto de los -reales y posibles- mecanismos artísticos y las prácticas sociales vinculadas a un espacio de arte contemporáneo. También nos invitan a reflexionar en torno a qué entendemos por museo. ¿El edificio? ¿Las obras de arte? ¿El reconocimiento social? A partir de preguntas como estas, son proyectos que tensionan una concepción conservadora y tradicional respecto de lo que es y debería ser un museo. Además, al plantear estas mismas interrogantes, ambos proyectos invitan a que, la próxima vez que visitemos uno de estos espacios, nuestra experiencia sea diferente.

En el catálogo Alfredo Jaar. The way it is, Jan Ketz escribe: "The task of a public interventionist is to interrupt, to insist, to disturb casual looking by demanding to be $\operatorname{seen}^{\text {"28 }}\left({ }_{53}\right)$. Me parece que esto es, precisamente, lo que generan Jaar y Gamarra con sus respectivos museos al ocupar -del modo en que lo hacen- el espacio público. Ketz menciona, también, que un rasgo característico de este tipo de intervenciones artísticas es que muchas de ellas suelen contar con una agenda o un propósito activista. Como hemos visto, la premisa política que moviliza tanto al LiMAC como a The Skoghall Konsthall es que un espacio de exhibición de arte es fundamental no solo para el mundo artístico, sino también para la ciudad y sus habitantes. Ahora bien, a pesar de esta coincidencia, no hay que perder de vista que, mientras el museo de Jaar es más bien dramático y aleccionador, el proyecto de Gamarra tiene un sentido irónico e incluso lúdico.

Como hemos visto, con el fuego de The Skoghall Konsthall, Alfredo Jaar intenta iluminar y defender su potencialidad crítica y su importancia social, mientras que con "Mantareina" Sandra Gamarra se pregunta por la compleja relación entre arte y consumo, y de paso visibiliza y tensiona a la distancia -cultural, artística, económica, etc.- entre dos metrópolis como Lima y Madrid. Interrogantes no resueltas del todo, pero que se enuncian desde dos museos que -uno quemado y el otro reacio a serlo de verdad- hacen de la estrategia de la negación su herramienta más elocuente.

\footnotetext{
27 "También es importante averiguar si es que el museo ficticio puede o no entregar nuevas luces respecto a los mecanismos del arte, a la vida artística y la sociedad. Planteo la pregunta con mi museo. Por lo tanto, no considero necesario generar una respuesta" (Trad. de la autora).

28 "La tarea de una intervención pública es interrumpir, insistir, perturbar una mirada casual por medio de una demanda por ser vista" (Trad. de la autora).
} 


\section{REFERENCIAS}

Augé, Marc. Los no-lugares. Espacios del anonimato. Barcelona: Gedisa, 2008.

Copeland, Mathieu, Balthazar Lovay (eds.). The Anti-Museum: An Anthology. Colonia: Verlag Der Buchhandlung Walther Konig, 2017.

Corris, Michael. "White out. Alfredo Jaar's Lament for los Images". Art Monthly, Oct. 2002: 6-IO.

Doherty, Claire. Public Art (Now): Out of Time, Out of Place. London: Art Books Publishing, 2015.

Estévez, Ruth. "Sandra Gamarra". Código. Web: https://cutt.ly/bRoEeaR. Acceso: o8-o8-20I8.

Gallardo Saint-Jean, Ximena. Museo de copias. El principio imitativo como proyecto modernizador. Chile, siglos XIX y XX. Santiago: Editorial Universidad Alberto Hurtado, 2016.

Gamarra, Sandra. "Emergencies Catalogue, Castilla y Leon Museum of Contemporary Art, 2005". Galería Leme. Web: https://cutt.ly/VRoEutg. Acceso: o8-o8-20I8.

Godoy Vega, Francisco. "Ante los museos de Alfredo Jaar". Crítica. Web. https://cutt.ly/VRoEazp. Publicación: 07-07-2010. Acceso: 02-08-2018.

LiMAC, http://li-mac.org/es/. Acceso: o8-o8-20I8.

Philips, Patricia C. "The Aesthetics of Witnessing: A Conversation with Alfredo Jaar". Publicart. Web. https://cutt.ly/zRoEkzl. Acceso: o8-o8-2018.

Thorp, Scott. "Alfredo Jaar: A Model of Thinking". Art Pulse Magazine. Web. hetps://cutt.ly/PRoEWuz. Acceso: o8-o8-20I8.

Schweizer, Nicole. "La política de las imágenes. Un recorrido a guisa de introducción". Alfredo Jaar. La política de las imágenes. Santiago: Metales Pesados, 2008.

Valdés, Adriana. "«No pienses como un artista, piensa como un ser humano». Apuntes para una poética de Alfredo Jaar". Memorias visuales. Arte contemporáneo en Chile. Santiago: Metales Pesados, 2006.

Valdés, Adriana. "Alfredo Jaar. «Soy un arquitecto que hace arte»". ARQ. 70, diciembre, 2008: I2I5.

Vidler, Anthony, "Vagabound Architecture". The Architectural Uncanny. Cambridge y Londres: MIT Press, 1992. 